\title{
Careers in optics project: building around existing resources
}

\section{A.-Sophie Poulin-Girard, G. Thériault, Véronique Zambon}

A.-Sophie Poulin-Girard, G. Thériault, Véronique Zambon, "Careers in optics project: building around existing resources," Proc. SPIE 8481, Optics Education and Outreach II, 84810N (15 October 2012); doi: $10.1117 / 12.929898$

SPIE Event: SPIE Optical Engineering + Applications, 2012, San Diego, California, United States 


\title{
Careers in optics project: building around existing resources
}

\author{
A.-S. Poulin-Girard*, G. Thériault and V. Zambon \\ Center for Optics, Photonics and Lasers, Université Laval, Québec, Canada, GIV $0 A 6$
}

\begin{abstract}
Many resources are available for groups that are interested in doing outreach activities with high school students. Most of these resources are dedicated to the experimentation of optical phenomena but do not include information about careers in optics and photonics. Created in 2010 for the Canadian Institute for Photonic Innovations (CIPI), the Canadian Photonic Kit was distributed throughout Canada. Using this kit as a starting point, Université Laval's OSA and SPIE student chapters, helped by the CIPI-Student network, will create a multi-platform resource addressing three subjects: (1) optical phenomena, (2) research in optics and photonics, and (3) related careers. This paper presents a timeline of the project and its main parts: the Canadian Photonic Kit and an expansion pack related to careers, a demonstration laboratory located within a research center and its virtual tour, and printable material for teachers and guidance counselors.
\end{abstract}

Keywords: Outreach, careers, demonstration laboratory, guidance counselors

\section{INTRODUCTION}

Various kits, experiments and materials are available, often for free, for organizations that do outreach in optics with teenagers. Most of the time, these kits need to be adapted to the specific clientele according to age, location and even language. When the members of Université Laval's SPIE and OSA student chapter received the Canadian Photonic Kit produced by the Canadian Institute for Photonic Innovations (CIPI), they decided to test the kit in a classroom of grade 11 high school students strictly following the instructions given in the kit. Afterwards, the students answered a short feedback quiz about the kit and were encouraged to give their comments, both positive and negative.

Using the CIPI Canadian Photonic Kit as a starting point and inspired by the comments and evaluations of our grade 11 students and previous comments and suggestions obtained from teachers and guidance counselors, we decided to enhance the contents of the kit using resources that we already had and to create material to complete the resource. Since we often receive requests from teachers and students in search of information about careers in optics and photonics, we decided to add outreach material specifically related to careers.

The article is divided as follows. The first section presents the CIPI Canadian Photonic Kit, and the second section highlights the features that have been added or will be added to the kit. The last section provides advice for people who are interested in building new outreach activities around existing resources to fit their clientele.

\section{CIPI CANADIAN PHOTONIC KIT}

After a study conducted by Université Laval highlighting the fact that $95 \%$ of 16 to 18 year-old students do not have enough information about photonics to consider it as a potential field of study, the Canadian Institute for Photonic Innovations decided to carry out the project of a bilingual kit containing seven interactive experiments about optics [1]. Since February 2011, more than 50 kits have been distributed all around Canada to "kit keepers" in universities, nonprofit organizations, colleges and museums so that it is now easy for students and professionals in the field of optics to do outreach activities in their community. The list of the kit keepers is available online [2]. The kit is shown in Fig. 1.

*anne-sophie.poulin-girard.1@ulaval.ca; phone 1418 656-2131 ext. 4584

Optics Education and Outreach II, edited by G. Groot Gregory, Proc. of SPIE Vol. 8481

84810N · C 2012 SPIE · CCC code: 0277-786/12/\$18 · doi: 10.1117/12.929898 


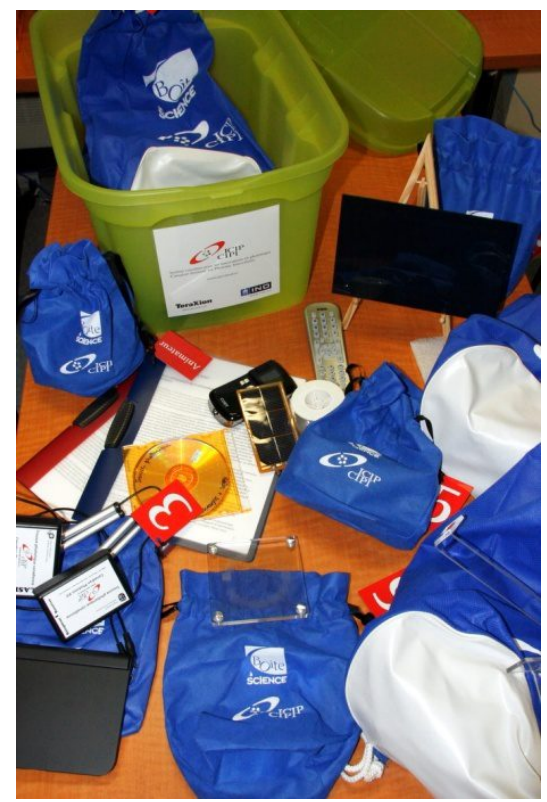

Figure 1. CIPI Canadian Photonic Kit is small and light and available in French and English in more than 50 universities, colleges, non-profit organizations and museums around Canada.

The activity, lasting approximately 1 hour, starts with a short presentation of the field of optics and photonics by the presenter and an explanation of the phenomena pertaining to the laser. Afterwards, the group is divided into six teams and each of them receives one or two bags containing materials and instructions to conduct an experiment. After a short period, each team is invited to come in front of the classroom and present their experiment to the rest of the group. At the end of the activity, the presenter answers a few questions from the students. The following sub-sections describe the seven experiments that are included in the CIPI Canadian Photonic Kit.

\subsection{Light $=$ movement}

This experiment contains a radiometer, as shown in Fig. 2, and a flash light. A radiometer is a glass bulb with a low vacuum containing a propeller with four light vanes, each of them having a white side and a black side. When the black side absorbs light, it heats up the gas at the edges of the vane. The gas then flows around the vane to equalize the pressure, making the propeller turn [3].

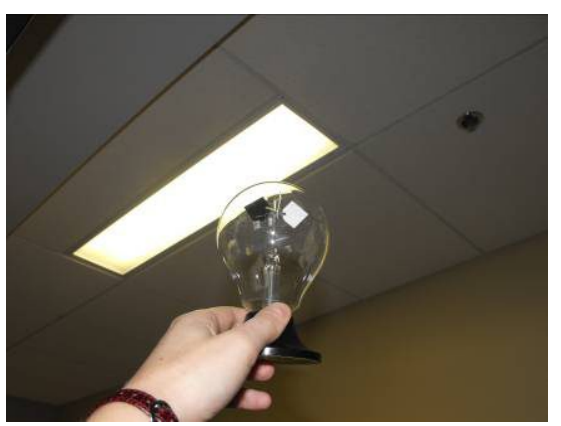

Figure 2. Radiometer used in the CIPI Canadian Photonic kit. 


\subsection{Invisible light}

In this experiment, students use a small solar panel linked to a piezoelectric buzzer. As expected, the students see that the white light of a flash light on the solar panel leads to a sound from the buzzer. However, they are surprised to learn that infrared light, which we cannot see with our naked eye, can also activate the buzzer. Moreover, they use a TV remote control to produce a series of strange sounds with the buzzer. A digital camera is available to actually see infrared light from the TV remote control because the sensor of the camera is sensitive to these wavelengths.

\subsection{A bright sound}

Information can be encoded in light; this is what the students discover in this experiment. They use an MP3 player connected to a laser and a receiver connected to a speaker. With a simple and quick alignment of the laser beam towards the receiver, the music can be heard in the speaker. The students also have mirrors that they can use to change the path of the laser beam.

\subsection{Deep reflections}

Total internal reflection (TIR) is a phenomenon that is often taught to high school students but even if you already have some theoretical knowledge in the matter, it is always interesting to see demonstration of this principle. In this experiment, students use a red laser to produce TIR in a bent acrylic stripe. They are also introduced to a special waveguide: water. Using a solution of powdered milk in water and a bottle with a small hole, light from the laser follows the path of the water-jet that comes out of the bottle, as shown in Fig. 3.

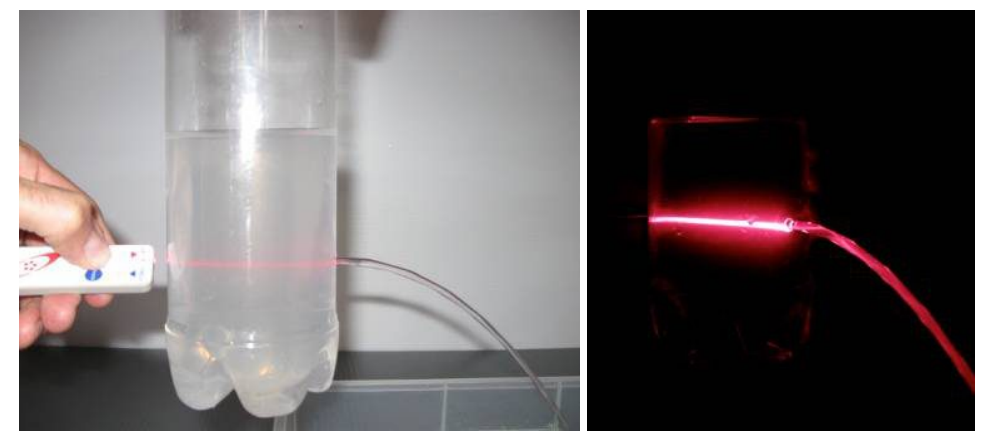

Figure 3. Total internal reflection in a water-jet. The solution is made of water and powdered milk to better visualize the laser beam's path through the liquid.

\subsection{Bundle of light!}

This experiment is inspired by common objects in which optical fibers have been introduced to create effects with light like some Christmas trees and lamps. A dozen pieces of equal length of simple plastic fishing line are inserted in one end of a short straw. By lighting the other end of the straw with a flashlight, the end of the fishing lines light up because they act as a waveguide.

\subsection{Unexpected images}

In this experiment, students use diffraction gratings to produce light patterns on the wall. Gratings engraved on a flexible plastic piece are easy to find and cheap to buy. To make them more durable, they are placed between two pieces of acrylic joined by screws as seen on Fig. 4 . 


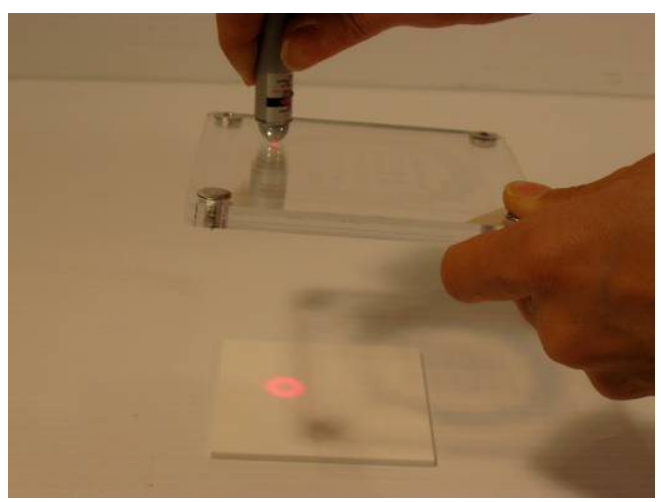

Figure 4. Different diffraction gratings placed between two pieces of acrylic to make them durable.

\subsection{Moving images}

In "Moving images", the students discover a digitally-manufactured hologram made by the company Rabbit Hole [4]. This company offers a vast range of holograms, from Terminator 2 to artwork. In this case, using a halogen lamp, the students discover a racing car turning into running shoes as they change the incidence angle of the light and their point of view.

\section{THE CAREERS PROJECT}

Because of the lack of information about careers in optics and the requests of teachers and guidance counselors for that information, we had been thinking about creating an outreach activity about careers for more than 2 years. After looking at and trying the CIPI Canadian Photonic Kit, we realized that it was the perfect starting point for our project. The five major aspects of the project will be described in the following sub-sections: (1) Updates and new experiments for the kit, (2) Videos about careers for an alternative way to use the kit, (3) Demonstration laboratory at Université Laval, (4) Resources for teachers and guidance counselors and (5) Website.

\subsection{Updates and new experiment for the kit}

Updates of the kit are the result of the comments that we received from the high school students and our observations during the test in their classroom. All the updates have already been sent to all the kit-keepers in Canada.

The first thing we decided to do was to replace all unsafe lasers with class 2 lasers. It is very important to use a laser of adequate power while doing outreach. It enhances the safety of the activity and encourages good practice and awareness of the dangers of lasers. Some manipulations have also been modified to reach the same goal.

Experiment 1, about light and movement, was too short to do compared to the others. Developing the same idea, we decided to add a portable laser light show that is easy to put together. It is made of a piece of plastic pipe, a nitrile membrane to cover one end of the pipe, a mirror fixed to the membrane with a magnet and a laser and a bracket to point the laser beam at the mirror. With the reflection of the laser towards a wall, when somebody talks in the open end of the pipe, shapes are drawn with light. Fig. 5 shows the device and the results of the light pattern on the wall. 


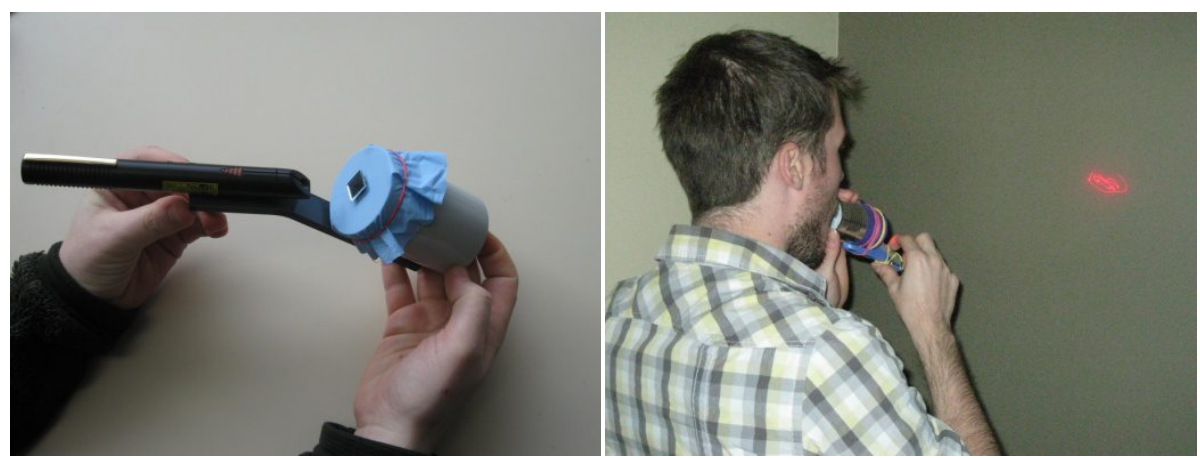

Figure 5. Portable laser light show.

Another experiment was too short for the length of the activity. The experiment "Bundle of Light" was interesting, so we decided to keep it and to combine it with "Deep Reflections". Both experiments are about waveguides and the duration of these two experiments when combined is perfect for the timing.

We realized that the topic of polarization was missing from the kit. We created an eighth experiment called "Polarized Light". It contains three parts. In the first one, students are introduced to polarizers and polarized light from common objects like calculators, digital watches and cell phones. They also use a polarizer to discover a hidden part of an image of a polarized card as shown in Fig. 6. In the second part, they build a polariscope by putting a transparent object between two polarizers. It is an interesting way to see internal stresses in materials. In the last part, they use a calcite crystal to discover birefringence. Placed over a text, the calcite crystal will refract the text twice because of the birefringence. One image or the other can be selected by using a polarizer and choosing the right orientation. This experiment uses, among other things, the kit's 'Magic stripes' made by the University of Rochester's OSA section.

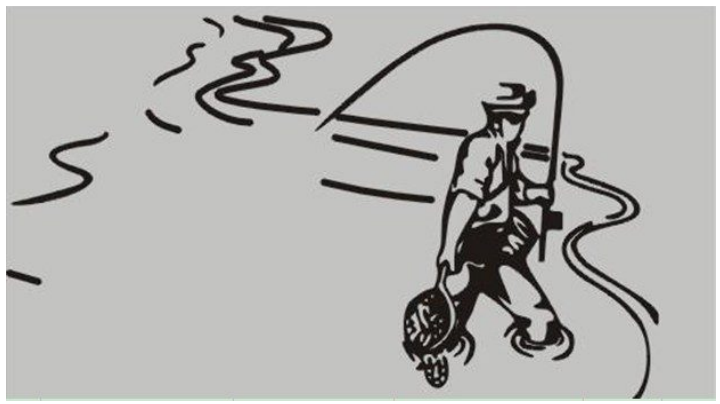

Without polarizer

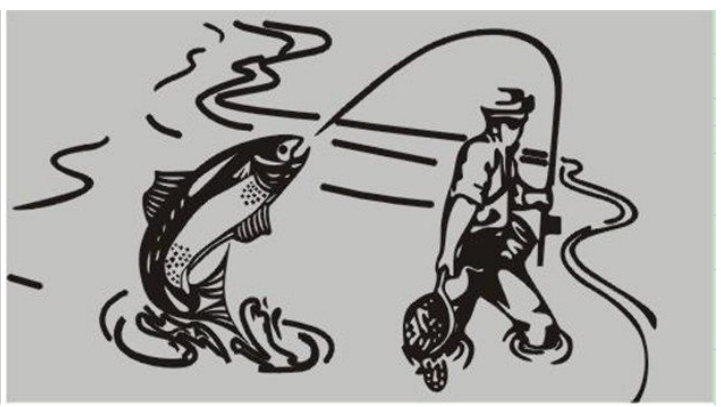

With polarizer

Figure 6. By placing one polarizer in front of the picture of a fisherman and rotating it, we can see the fish appear and disappear.

Of course, all the instructions have been modified to fit the changes made.

\subsection{Videos about careers in optics}

From the beginning, our main goal was to provide Canadian students information about studies and careers in optics and photonics. Based on recurring comments to the effect that students were shy about presenting their experiment in front of the group and that the group had difficulties in seeing the material and understanding the experiment during the presentation, we thought of an alternative way to use the kit. We designed an "Expansion pack on careers in optics" which will be available for all the kit-keepers in autumn 2012. Available in French and in English, the tool consists of 7 videos of a length of 4 minutes each that replace the presentations of the students. Each video contains a clear demonstration of one or two experiments, an interview with a professional or a student in the field of optics and technical information about his or her occupation. Table 1 lists each experiment and their related careers. 
Table 1: Content of the videos about careers in optics

\begin{tabular}{|c|c|l|}
\hline Experiment(s) presented & Career or occupation & \multicolumn{1}{|c|}{ Professional } \\
\hline Light $=$ movement & Sales representative & René Dionne, TeraXion \\
\hline Invisible light & Professor/Researcher & David Plant, McGill University \\
\hline A bright sound & Engineer in a company & Geneviève Taurand, Gentec-EO \\
\hline Deep reflection \& Bundle of light! & Technician & Nicolas Grégoire, Center for Optics, Photonics and Lasers \\
\hline Unexpected images & Entrepreneur & Xavier P. Godmaire, Laserax \\
\hline Moving images & Graduate student & Gabrielle Thériault, PhD Candidate, Université Laval \\
\hline Polarized light & Teacher & Jason Grenier, lecturer, University of Toronto \\
\hline
\end{tabular}

\subsection{Demonstration laboratory}

When the members of our student chapter go into a classroom to lead outreach activities, high school students are always curious about our day-to-day work. It is hard to explain it, because it is different from one day to another and the research environment is difficult to describe to neophytes. Two year ago, two graduate students, realizing the need for outreach facilities within in our research center, decided to create a holography laboratory with the help of other students, professionals employed by our center and the financial support of more than 13 sponsors. This laboratory, located in the Pavilion of Optics and Photonics at Université Laval, opened in October 2010 and has welcomed more than 800 visitors to this day: middle school, high school, college and undergraduate students, teachers and guidance counselors.

In addition to a holography set up, the laboratory also contains a portable fiber optics set-up showing total internal reflection, a preform with a Cobalt-doped core, infrared transmission of chalcogenide glass and a wireless optical communication system. To complete this experiment, information will be added about manufacturing processes of optical glasses and fiber optics. In the next two years, we will add three more experiments: (1) an oxymeter working with LabView to measure optically the level of oxygen in the blood, (2) an adaptive optics set-up to correct simulated atmospheric turbulence and (3) a webcam in a partner company to show live laser cutting processes and enable interaction with the workers in the company. A poster explaining the different phenomena involved accompanies each experiment.

\subsection{Resources for teachers and guidance counselors}

Our mother tongue being French, they are very few resources available in this language to put in the classroom, most of them being in English. To address this issue, we will create a series of four posters available in French or in English containing pictures and information about specific topics. We chose four topics that we thought were important and interesting: polarization, fiber optics, fluorescence and colors of light. During the last edition of the Photonic Games in October 2011, an optics competition for grade 11 students, a photography contest was organized around the four topics [5]. Pictures were selected to be featured on the poster about fiber optics and colors of light. Also, a picture from 2009 Photonic Games was selected for the fluorescence theme. Fig. 7 shows the four pictures selected. 


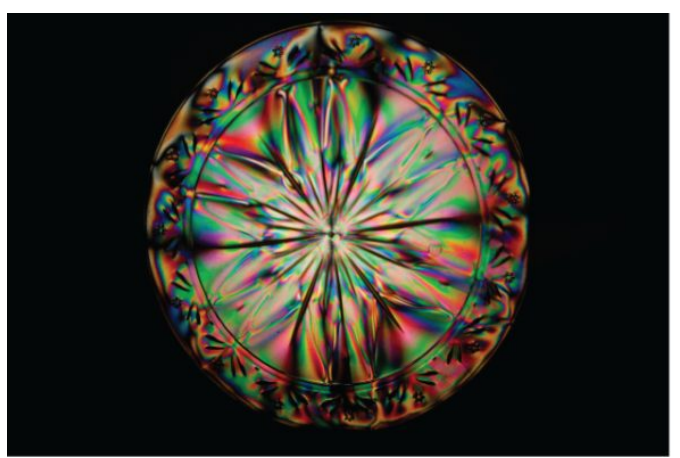

(a)

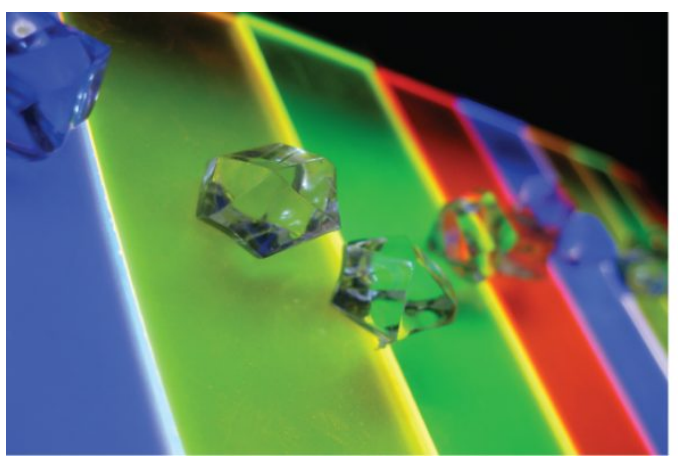

(c)

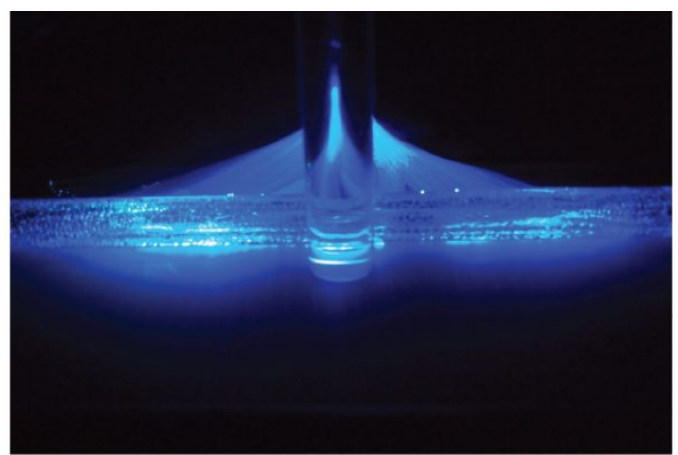

(b)

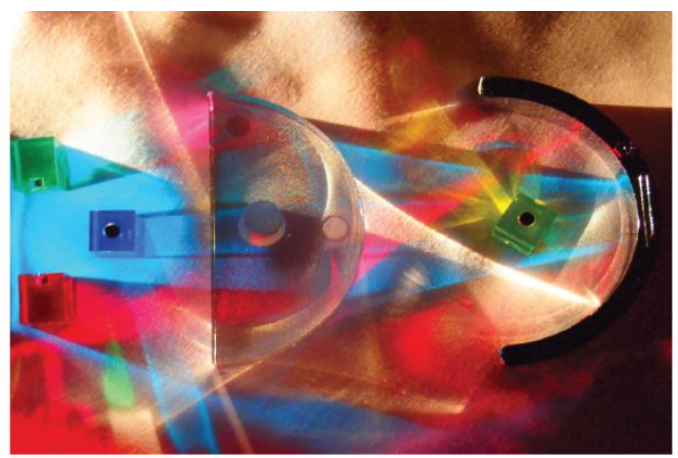

(d)

Figure 7. Pictures selected for the posters for (a) polarization, (b) fiber optics, (c) fluorescence and (d) colors of light.

To match our videos about careers, we will produce a brochure in collaboration with a guidance counselor to present the careers and occupations listed in Table 1. We want this brochure to be a source of information for students but also for guidance counselors, which is a challenge. The brochure will present the same professionals as in the videos to continue along the same line and ensure a coherent resource. Work will be carried out with other students from the different provinces of Canada to include specific information if necessary. This brochure will also be available in French and in English.

\subsection{Website}

The Internet has become a powerful tool that cannot be ignored. To make sure that all the resources are available to as many people as possible, information about the content of the CIPI Canadian Photonic Kit, the list of kit keepers, videos about careers, printable material such as posters and documents for guidance counselors will be placed online on the project's website.

To open the doors of the demonstration laboratory to all Canadians, we will put a virtual tour with hot spots online, trying to make it as realistic as possible. To encourage other universities to build their own outreach facility, we will create protocols detailing the material needed for each of the five experiments and the steps for setting them up. We will also include tips from our own experience in the creation of those experiments. 


\section{BUILDING AROUND EXISTING RESOURCES}

When we had the idea of conducting a project about careers in optics and photonics, we decided to use the CIPI Canadian Photonic Kit as the starting point. Here is our advice for people who want to build outreach activities around existing resources.

\subsection{Choose the starting point wisely}

When we received the CIPI Canadian Photonic Kit, we realized that it had great potential. The experiments were interesting, the concept was different, various optical phenomena were explained, and the major advantage of this kit was that it was distributed to more than 50 kit-keepers around Canada. It represented a perfect opportunity for us to build new material that could be sent all around Canada to reach as many people as possible. Our activities are usually in French, therefore hard to export. This time, however, the resource being bilingual, we had the opportunity to create a new resource in French to use within our community, but also in English to share with the rest of the world.

\subsection{Determine the needs of the community}

The idea of a project about careers came from a need expressed mostly by students, teachers and guidance counselors. If we succeed in creating a resource that answers this need, people will want to work with it therefore increasing awareness about optics and photonics to the users. To make sure we reach this goal, it is important to maintain communication with the community. We will test the kit again this autumn with high school students to obtain feedback and see if we are still on the right track.

\subsection{Find a sponsor that fits your idea}

We were lucky to work with a kit that already had a sponsor, the Canadian Institute for Photonic Innovations (CIPI). We presented the project to their Board of Directors and were able to get more than $\$ 50 \mathrm{~K}$. One interesting aspect of the project is that funding was set aside to pay students to perform the different tasks of the project. This aspect was important to us, to have the job done mostly by students and to be able to pay them for their work. It was an idea that our sponsor liked and, since we had our hearts set on it, it was essential to be on the same page. Of course, sometimes compromises have to be made to fit the sponsor's view of the project to ours.

\subsection{Dream}

We held a few brainstorming sessions where everybody in the research center was invited before we arrived at our final concept. The main goal of these meetings was to express any idea. If somebody had told us a year ago that we were going to manage a $\$ 50 \mathrm{~K}$ program, we would have laughed at the time. Share your ideas, even the craziest, you may find someone who will support your project.

\section{ACKNOWLEDGEMENTS}

We would like to thank Robert Corriveau, Pierre Bolduc and Heidi Turcot who helped us update the CIPI Canadian Photonic Kit and for their advice in starting the project about careers in optics. We would like to thank CIPI and CIPI-S for financially supporting the project from the start. We would also like to thank Professor Réal Vallée for his support in this project and the Center for Optics, Photonics and Lasers (COPL) for providing the facilities for the demonstration laboratory. Finally, we would like to thank Pierre L’Espérance who made the videos about careers in optics. 


\section{REFERENCES}

[1] Canadian Institute for Photonic Innovations website, "Why a Photonic Kit?" http://www.cipi.ulaval.ca/index.php?id=333, retrieved in May, 2012.

[2] Canadian Institute for Photonic Innovations website, "Kit keepers," http://www.cipi.ulaval.ca/index.php?id=336, retrieved in May 2012

[3] "How does a light mill work?" http://www.weburbia.com/physics/light-mill.html, retrieved in May, 2012.

[4] Rabbit Hole, 3D Motion Holograms, http://www.rabbitholes.com/, retrieved in May 2012

[5] A.-S. Poulin-Girard et al., Photonic games: hands-on challenges to spark teenagers' interest in light, First Conference on Optics Education and Outreach, Proc. SPIE 7783, 77830A (2010); 